\title{
Narrativas Discursivas das Empresas Fumageiras Instaladas no Vale do Rio Pardo (RS): um Estudo sobre Poder e Território
}

Ana Flávia Marques ${ }^{1}$

\begin{abstract}
Resumo
Enquanto empresas mais representativas em termos de geração de empregos e renda na Região do Vale do Rio Pardo (RS), as fumageiras constituem-se na personificação da ação territorializadora do capital sobre os espaços. Seus discursos oficiais são monólogos que fortalecem a dominação do capital sobre as sociedades, naturalizando injustiças socioambientais. A pesquisa desenvolvida ocupou-se em, por meio da metodologia da análise crítica do discurso, estudar as narrativas de quatorze empresas fumageiras, discutindo suas implicações no desenvolvimento da região, visando fornecer instrumentos para o fortalecimento dos atores locais e da escala regional, bem como das forças horizontais que garantem um contraponto à homogeneição globalizadora dos territórios. Conhecer as narrativas dessas empresas, que convertem os bens ambientais em recursos de produção monocultora voltada à exportação e que geram externalidades socioambientais negativas não contabilizadas nos balanços econômicos, é etapa fundamental para a emergência de vozes plurais, com léxico próprio e adequado à compreensão da realidade pelo conjunto de seus atores.
\end{abstract}

Palavras-Chave: Agroindústrias Fumageiras. Análise Crítica do discurso. Sustentabilidade socioambiental. Justiça ambiental.

\begin{abstract}
The tobacco companies are the most representative companies in terms of job generation and income in the Vale do Rio Pardo Region (RS). They constitute the personification of the territorialisation of capital over spaces. Their official speeches are monologues that strengthen the domination of capital over societies, naturalizing social and environmental injustices. The research carried out focused on the methodology of the critical analysis of the discourse, studying the statements of fourteen tobacco companies, discussing their implications for the region's development, aiming to provide instruments for the strengthening of local and regional actors, as well as of the horizontal forces that guarantee a counterpoint to the globalization homogenization of the territories. Knowing the discourses of these companies, which convert environmental goods into monoculture production resources geared to exports and which generate negative socio-environmental externalities that are not accounted for in the economic balance sheets, is a fundamental step for the emergence of plural voices, with its own lexicon and adequate to the understanding of reality by the group of its actors.
\end{abstract}

Keywords: Tobacco agro-industries. Critical analysis of discourse. Social and environmental sustainability.Environmental justice.

\footnotetext{
${ }^{1}$ Doutora em Ciências. Professora do Programa de Pós-Graduação em Desenvolvimento Regional da Universidade de Santa Cruz do Sul (UNISC). afmarques@unisc.br
} 


\section{Introdução}

A agenda socioambiental tem estado cada vez mais presente nas políticas públicas, porém isso não significa que os conhecimentos sobre o meio biofísico e os impactos ambientais negativos do modelo de produção/acumulação estejam contribuindo para a superação de barreiras econômicas, políticas e ideológicas, ou culminando na construção da justiça ambiental ${ }^{2}$.

Diante de um contexto Pós-Moderno fortemente marcado pela crise socioambiental, percebe-se nos modelos de crescimento e desenvolvimento - na maioria das vezes impostos pela superestrutura do capital às regiões - dicotomias que caracterizam a contraposição entre conservacionismo e produtivismo.

Neste cenário, progressivamente, e especialmente desde meados do século $X X$, as organizações produtivas - como entidades protagonistas do processo de apropriação social da natureza e transformação dos bens ambientais em 'recursos naturais' - têm sido conduzidas a assumir papeis voltados à construção de relações socioambientais responsáveis e sustentáveis. Tal 'condução' se dá por pressão social do Estado, na forma de regulamentações, e pelos mecanismos informais de pressão exercidos pelas sociedades e pelo mercado.

Como atesta a realidade trágica das alterações climáticas, seguida por desastres ditos 'naturais', perda de habitas e extinção de espécies, miséria, fome, propagação de doenças e acirramento das desigualdades sociais, as transformações não têm ocorrido com o impacto necessário e urgente. As organizações produtivas continuam espelhando em suas práticas a dominância de um modelo racional assentado na busca pelo lucro imediato, sem a observância de limites, ferindo a capacidade de suporte dos ecossistemas e, consequentemente, comprometendo a existência da vida.

As indústrias fumageiras são as empresas mais representativas em termos de geração de empregos e renda da Região do Vale do Rio Pardo - território assentado na porção

\footnotetext{
2 Nos termos de Acselrad, Herculano e Pádua (2004-b), justiça ambiental compreende um conjunto de princípios que garante, de forma indiscriminada, o fim da desproporcionalidade na degradação do espaço coletivo. Considerando-se ocorrência de mecanismos sociopolíticos capazes de destinar "a maior carga de danos ambientais do desenvolvimento a grupos sociais de trabalhadores, populações de baixa renda, segmentos raciais discriminados e parcelas marginalizadas da cidadania" (ACSELRAD, HERCULANO; PÁDUA, 2004-b, p. 9-10), este conceito é bastante caro para a pesquisa aqui relatada.
} 
central do estado do Rio Grande do Sul, recorte espacial da análise aqui apresentada - a qual é composta por 23 municípios $^{3}$. Sua ação na região implica na geração de aspectos e impactos socioambientais que se iniciam nas propriedades rurais (plantio e manejo das lavouras; colheita, armazenamento e secagem das folhas de fumo) e chegam às empresas de beneficiamento do tabaco.

Essas empresas e todo o contexto de produção rural da qual dependem são alvos de críticas severas já há muitas décadas, especialmente quanto ao seu propósito - produção de cigarros: produtos que causam dependência e estão associados ao desenvolvimento do câncer, dentre outras doenças - e aos processos de produção, que envolvem o uso de agroquímicos nas lavouras, manipulação genética de sementes, adubação química do solo, queima de madeira nas estufas e o trabalho sazonal na indústria.

Diante deste quadro de pressão e de questionamentos sobre sua própria razão de ser - corporificado nas discussões da comunidade internacional sobre o gradativo encerramento da produção de tabaco -, as fumageiras precisam enquadrar-se em quantidade significativa de normas socioambientais e, são consideradas por alguns autores da área de gestão socioambiental, como pioneiras na busca pela construção de modelos mais sustentáveis do ponto de vista do ambiente e das sociedades. Grande parte desta imagem 'sustentável' deriva de um discurso 'verde' que é construído dentro do contexto da racionalidade do capital e que permanece e se difunde entre a comunidade empresarial, os produtores rurais e parcela da sociedade.

Analisar a forma (ou as formas) como as empresas fumageiras estão se apropriando dos saberes ambientais em seus discursos oficiais permite desenhar um quadro simbólico do potencial de transposição da humanidade com relação à crise socioambiental. A análise crítica dos discursos oficiais, divulgados nos meios de comunicação, especialmente nos relatórios públicos de sustentabilidade e responsabilidade social corporativa, permite identificar relações de dominação e poder que configuram processos de territorialização.

Assim, com o objetivo de identificar os saberes ambientais, bem como as relações de dominação e poder presentes no conteúdo destes discursos, foram analisados, a partir da

\footnotetext{
${ }^{3}$ A Região do Vale do Rio Pardo é entendida nesta pesquisa como formada pelos 23 municípios que compõem o Conselho Regional de Desenvolvimento (COREDE) do Vale do Rio Pardo, quais sejam: Arroio do Tigre, Boqueirão do Leão, Candelária, Encruzilhada do Sul, Estrela Velha, General Câmara, Herveiras, Ibarama, Lagoa Bonita do Sul, Mato Leitão, Pantano Grande, Passa Sete, Passo do Sobrado, Rio Pardo, Santa Cruz do Sul, Segredo, Sinimbu, Sobradinho, Tunas, Vale do Sol, Vale Verde, Venâncio Aires, Vera Cruz (FEE, 2016).
} 
metodologia de análise crítica do discurso, os materiais de comunicação oficiais disponibilizados pelo Sindicato Interestadual da Indústria do Tabaco (SindiTabaco). Estes materiais são ferramenta de comunicação das quatorze empresas instaladas na região, que são associadas ao Sindicato, e estavam disponíveis para consulta nos anos de 2017 e 2018 . O foco da análise desenvolvida foi a intertextualidade, permitindo discutir a produção de sentidos e a interiorização dos saberes ambientais nas empresas como instrumentos para a construção da sustentabilidade em sentido amplo.

O material analisado permitiu identificar (1) marcas discursivas que remetem à personalização do leitor e da instituição; (2) simulação de uma relação conversacional e autopromoção das empresas; (3) gênero híbrido de escrita, buscando o convencimento do leitor: características que marcam o gênero artigo acadêmico, como léxico-gramatical específicos, movimentos retóricos, identificação de autores e afiliação institucional, em hibridismo com afirmações de senso comum e improváveis de serem comprovadas cientificamente; (4) mercantilização do discurso e luta simbólica pela naturalização do senso comum; (5) a discussão socioambiental se desenha em torno de programas definidos pelo léxico considerado relevante para a agroindústria, valendo-se de termos com significado duplo, como 'sustentabilidade', que aparece como 'sustentabilidade do negócio', remetendo à sustentabilidade econômica; ou mesmo usando termos de modo errôneo, como ocorre com 'reflorestamento', referindo-se ao plantio de árvores exóticas com finalidade de uso nas estufas de secagem de tabaco.

Os resultados da pesquisa contribuem para os avanços na compreensão sobre a forma como o capital constrói territórios, especialmente por meio da globalização econômica e da injustiça socioambiental, que se expressa na degradação dos eco e sociossistemas. Para além disso, sendo o relato discursivo um mecanismo de narração da realidade, os resultados da pesquisa, quando apropriados pela comunidade regional, podem fortalecer a percepção de riscos e injustiças socioambientais, provocando movimentos para a construção coletiva de uma relação mais justa e equilibrada entre empresas e sociedade. 


\section{Protagonismo das Empresas Fumageiras nos Territórios: Conflitos, Riscos e Injustiças}

Compreendendo-se o território a partir de uma abordagem integradora, como proposta por Haesbaert (2004), deve-se considerar que, mais do que um recorte espacial, o território carrega em si, indissociavelmente, uma dimensão simbólica e cultural e uma dimensão material, de natureza político-econômica. Ou seja, o território é uma construção que se dá no jogo entre os macropoderes políticos institucionalizados e os micropoderes, muitas vezes mais simbólicos, produzidos e vividos no cotidiano das populações; para além disso, em razão de seu caráter integrador, o território é construído pelo Estado (quando este exerce seu como papel gestor-redistributivo) e pelos indivíduos e grupos sociais (em sua vivência concreta nos/com os ambientes).

Sendo as empresas atores importantes nas dimensões simbólico-culturais e políticoeconômicas, como entes simbólicos e materiais do capital, caracterizando-se como instituições socioeconômicas, pode-se afirmar que as mesmas exercem função decisiva na construção dos territórios (territorialização).

A Região do Vale do Rio Pardo ${ }^{4}$, no Sul do Brasil - recorte geográfico da pesquisa da qual resulta o presente artigo - historicamente tem sua identidade territorial ligada à indústria do tabaco ou ao chamado complexo agroindustrial do fumo, sendo conhecida, também, como 'território do fumo'.

A produção de tabaco na Região inicia em meados do século XIX, quando da chegada das famílias de imigrantes europeus, e passa a se destacar na economia mercantil das áreas coloniais gaúchas, possibilitando, nas décadas seguintes, o desenvolvimento de empresas locais responsáveis pelo processamento de tabaco e fabricação de cigarros, inicialmente nos municípios de Santa Cruz do Sul e Venâncio Aires (SILVEIRA, 2013).

Silveira (2013) afirma que foi na década de 1970 que, com a intensificação da internacionalização das empresas fumageiras nacionais, o processo de agroindustrialização do tabaco se intensificou, por meio da ampliação do cultivo, modernização no processamento e aumento na exportação do fumo em folha.

A partir deste marco temporal começa a emergir um processo de territorialização que pode ser compreendido em etapas que ocorrem quase simultaneamente: (1)

\footnotetext{
${ }^{4}$ Conformação da região apresentada na Nota de Rodapé número 2, na Introdução do presente artigo.
} 
significativo número de empresas de capital estrangeiro se instalam na região (inicialmente norte-americanas, alemãs e francesas), valendo-se dos bens ambientais (água, micronutrientes do solo e outros benefícios oferecidos gratuitamente pelos ecossistemas), do trabalho humano ${ }^{5}$ e, em algumas situações, de benefícios fiscais temporários, oferecidos em razão de estratégias políticas; (2) constitui-se o sistema integrado de produção agroindustrial que passa a definir e regular as relações econômicas e sociais entre os agricultores familiares, fumicultores e empresas agrofumageiras, mas também as relações entre esses agentes com inúmeros outros, como por exemplo, empresas fornecedoras de insumos químicos, mecânicos e biotecnológicos, bancos e instituições financeiras, transportadoras e seguradoras (SILVEIRA, 2013, p. 10); (3) consolidação da participação da região na rede internacional do tabaco, numa condição subalterna, uma vez que, segundo dados da Afubra discutidos por Virgínia Etges (2013), 85\% do tabaco produzido no sul do Brasil são exportados - exportação de bens primários - e somente $15 \%$ são transformados em subprodutos, como o cigarro - os quais têm valor agregado.

As empresas do ramo do tabaco assentadas na Região Sul do Brasil são predominantemente beneficiadoras do fumo em folha produzido em pequenas propriedades, por cerca de 150 mil famílias. No ano de 2017, a safra de fumo na Região Sul atingiu cerca de R\$̦6 bilhões, segundo dados da Associação do Fumicultores do Brasil (AFUBRA, 2018). [Ver Quadro 1].

\footnotetext{
${ }^{5}$ Aqui temos diferentes formas de exploração de trabalho. Destaca-se duas delas: o trabalho do produtor rural, que é exposto aos riscos inerentes à agricultura em monoculturas voltadas ao agronegócio, por exemplo, os riscos na manipulação e aplicação de agroquímicos tóxicos ao ambiente e, consequentemente, aos seres humanos; o trabalho do 'safrista', que é o colaborador sazonal, contratado pelas empresas somente para as épocas de safra.
} 
Quadro 1 - Evolução da Fumicultura no Sul do Brasil - 1995-2017

\begin{tabular}{|c|c|c|c|c|c|c|}
\hline SAFRA & $\begin{array}{l}\text { FAMÍLIAS } \\
\text { produtoras }\end{array}$ & $\begin{array}{l}\text { HECTARES } \\
\text { plantados }\end{array}$ & $\begin{array}{l}\text { PRODUÇÃO } \\
\text { toneladas }\end{array}$ & kg/ha & $\begin{array}{l}\text { VALOR } \\
\mathrm{R} \$ / \mathrm{kg}\end{array}$ & Total R\$ \\
\hline 2017 & 150.240 & 298.530 & 705.930 & 2.365 & 8,63 & 6.090 .633 .962 \\
\hline 2016 & 144.320 & 271.070 & 525.221 & 1.938 & 9,96 & 5.230 .364 .810 \\
\hline 2015 & 153.730 & 308.260 & 697.650 & 2.263 & 7,13 & 4.976.704.200 \\
\hline 2014 & 162.410 & 323.700 & 731.390 & 2.259 & 7,28 & 5.321.932.174 \\
\hline 2013 & 159.595 & 313.675 & 712.750 & 2.272 & 7,45 & 5.309 .987 .500 \\
\hline 2012 & 165.170 & 324.610 & 727.510 & 2.241 & 6,30 & 4.583 .313 .000 \\
\hline 2011 & 186.810 & 372.930 & 832.830 & 2.233 & 4,93 & 4.105 .851 .900 \\
\hline 2010 & 185.160 & 370.830 & 691.870 & 1.866 & 6,35 & 4.393.374.500 \\
\hline 2009 & 186.580 & 374.060 & 744.280 & 1.990 & 5,90 & 4.391.252.000 \\
\hline 2008 & 180.520 & 348.720 & 713.870 & 2.047 & 5,41 & 3.862 .036 .700 \\
\hline 2007 & 182.650 & 360.910 & 758.660 & 2.102 & 4,25 & 3.224 .305 .000 \\
\hline 2006 & 193.310 & 417.420 & 769.660 & 1.844 & 4,15 & 3.194.089.000 \\
\hline 2005 & 198.040 & 439.220 & 842.990 & 1.919 & 4,33 & 3.650 .146 .700 \\
\hline 2000 & 134.850 & 257.660 & 539.040 & 2.092 & 2,00 & 1.078 .080 .000 \\
\hline 1995 & 132.680 & 200.830 & 348.000 & 1.733 & 1,55 & 539.400 .000 \\
\hline
\end{tabular}

Fonte: Adaptado a partir de Afubra( 2018).

Em face da produção em larga escala, seria de se esperar que os valores financeiros revertessem na promoção do desenvolvimento da região, porém, os números revelam outra realidade. Ramos e Paiva (2005) demonstraram que a absorção das rendas produzidas pelo tabaco na Região do Vale do Rio Pardo (RVRP) correspondia a 36,15\%, enquanto a média no Rio Grande do Sul era de $50,99 \%$. Isso equivale a dizer que - somente - $36,15 \%$ do total da renda produzida na RVRP permaneciam na região ${ }^{6}$.

Para além do cenário socioeconômico mais evidente no processo de territorialização exercido pelas empresas fumageiras, mas adjacente a este, mesmo que numa situação de

\footnotetext{
${ }^{6}$ Não se dispõe de estudos mais recentes para uma discussão aprofundada dos reflexos da 'fuga' de renda, mas os indicadores de desenvolvimento da região, disponibilizados pela Fundação de Economia e Estatística/RS (FEE, 20028) não parecem atestar uma mudança nesse cenário.
} 
não tão óbvia correlação, observa-se a emergência de um conjunto de conflitos socioambientais ${ }^{7}$ que dizem respeito ao uso de território.

Os conflitos socioambientais surgem a partir da disputa pela apropriação do mundo material - dos bens ambientais existentes no território e do próprio território em si, como recorte espacial - exercida pelas forças políticas, econômicas e sociais. Conflitos desta ordem também emergem quando um determinado grupo social se percebe numa condição de risco $^{8}$, seja ele ambiental, social e ou econômico. Com relação aos riscos socioambientais, muitas vezes eles não geram conflitos, embora claramente existam. Isso ocorre porque o grupo social a eles exposto não é capaz de percebê-los ou é deliberadamente levado a ignorá-los.

Na seara dos estudos de conflitos e riscos na RVRP, encontra-se a pesquisa de Marques e Bublitz (2016) que, em um intervalo de tempo de dez anos, de 2004 a 2014, identificaram e categorizaram os conflitos socioambientais existentes na área urbana de Santa Cruz do Sul - o maior município da RVRP em termos de área territorial e de número de habitantes - e os relacionaram à injustiça ambiental ${ }^{9}$. As pesquisadoras vincularam parte dos conflitos identificados ao processo de territorialização exercido pelas indústrias fumageiras. Esses conflitos estão relacionados especialmente ao adensamento urbano desvinculado de planejamento, ocorrido em curtos intervalos de tempo. Esse processo resultou na ocupação

\footnotetext{
${ }^{7}$ A "sociologia da questão ambiental", assim denominada por Henri Acselrad (2004, p. 17), tem encontrado dificuldade para caracterizar as especificidades dos conflitos ambientais enquanto objetos científicos de análise, existindo muitas possibilidades de conceituação, umas mais evolucionistas, entendendo que os conflitos se referem às diferentes respostas de distintos grupos sociais às pressões ambientais; outras mais economicistas, relacionadas à ação do mercado sobre os bens ambientais presentes ou ausentes nos territórios; e, escapando a tais paradigmas, uma série de doutras possibilidades de conceituação. Nesta pesquisa, construímos uma acepção própria para o termo "conflitos", agregando a adjetivação "socioambientais", e partindo das ideias integradoras de Henri Acselrad em suas diferentes obras sobre Justiça Ambiental.

${ }^{8}$ A concepção de risco adotada aqui é, aquela defendida por Yvette Veyret (2007, p11): “O risco, objeto social, define-se como a percepção do perigo, da catástrofe possível. Ele existe apenas em relação a um indivíduo e a um grupo social ou profissional, uma comunidade, uma sociedade que o apreende por meio de representações mentais e com ele convive por meio de práticas específicas. Não há risco sem uma população ou indivíduo que o perceba e que poderia sofrer seus efeitos. Correm-se riscos que são assumidos, recusados, estimados, avaliados, calculados. O risco é a tradução de uma ameaça, de um perigo para aquele que está sujeito a ele e o percebe como tal. "

9 O termo 'injustiça ambiental' surge em decorrência das análises no campo da justiça ambiental. “(...) [E]ntende-se por justiça ambiental a condição de existência coletiva própria a sociedades desiguais onde operam mecanismos sociopolíticos que destinam a maior carga de danos ambientais do desenvolvimento a grupos sociais de trabalhadores, populações de baixa renda, segmentos raciais discriminados, parcelas marginalizadas e mais vulneráveis da cidadania (ACSELRAD, 2004-a, p. 09-10).
} 
de áreas sujeitas a escorregamento e deslizamento de terras, enchentes, poluição industrial e distantes geograficamente da infraestrutura de serviços, como saúde e educação.

Como evidenciado pelas pesquisadoras, certamente as indústrias fumageiras não são os únicos atores do cenário apresentado, porém é indiscutível o seu protagonismo, exercido especialmente na atração de população para as cidades do Vale do Rio Pardo (êxodo rural e migrações), e na repulsão de parte desta população (majoritariamente aqueles indivíduos com rendas inferiores) para regiões ambientalmente frágeis e com acesso dificultado a serviços básicos, caracterizando um cenário de conflitos no uso do território urbano e de sua base de recursos, exposição a riscos e, consequentemente, de injustiça ambiental.

Pesquisas sobre conflitos, riscos e injustiça social e ambiental nas áreas rurais e urbanas $^{10}$ da região do Vale do Rio Pardo, tendo como foco a relação entre as comunidades locais e regionais e as indústrias fumageiras ${ }^{11}$, são desenvolvidos em larga escala, especialmente nos programas de pós-graduação das instituições de ensino superior da região ${ }^{12}$. Tais estudos abordam principalmente questões referentes à monocultura do tabaco e suas consequências socioeconômicas e ambientais; toxicidade dos agroquímicos e fertilizantes utilizados e seus impactos na saúde humana e nos ecossistemas; o papel da RVRP no complexo agroindustrial do fumo; as relações trabalhistas entre as agroindústrias do tabaco e os produtores rurais; o trabalho sazonal e suas implicações; dentre outros temas.

É preciso ressaltar que as formas como atuam as indústrias fumageiras na territorialização da RVRP têm mudado ao longo do tempo, refletindo as transformações do capitalismo e mesmo do modo como a sociedade local/regional se relaciona com o modelo agroindustrial de produção do tabaco.

Quando discute a produção capitalista do espaço, o geógrafo Harvey (2005), analisando a produção do espaço urbano - seu objeto principal de estudo - investiga o motivo pelo qual o capitalismo produz uma geografia histórica distintiva. Harvey analisa que, embora o processo urbano sob o capitalismo seja moldado pela lógica da circulação e

\footnotetext{
${ }^{10}$ Nas análises socioambientais acerca da produção dos territórios, os recortes rural e urbano praticamente deixam de existir, posto que aquilo que ocorre em um, influencia diretamente ao outro. $O$ ecossistema é um continuum rural-urbano.

${ }^{11}$ Os estudos desenvolvidos nem sempre se utilizam dos termos "riscos", "conflitos socioambientais" e “justiça/injustiça ambiental", porém, em uma análise de seu escopo, indiscutivelmente tratam de tais temas.

${ }^{12}$ O Programa de Pós-Graduação em Desenvolvimento Regional (PPGDR) da Universidade de Santa Cruz do Sul (UNISC) é conhecido nacional e internacionalmente por seu protagonismo nestas discussões.
} 
acumulação do capital, aqueles mesmos critérios modelam as condições e as circunstâncias da acumulação do capital, em pontos posteriores do tempo e do espaço, numa relação biunívoca. Esta reflexão permite pensar que os territórios, na fase mais recente do desenvolvimento capitalista, são tanto produtos como condições dos processos sociais de transformação em andamento.

Transpondo esta linha de pensamento para os discursos das empresas fumageiras entendendo-os como ferramentas do capital para a formação, consolidação e reprodução dos territórios - observa-se que os discursos influenciam e são influenciados pelo atual estágio de desenvolvimento do capitalismo e sua espacialização no território estudado; refletem e traduzem formas de reprodução de práticas sociais, de dominação e poder; e, ao mesmo tempo, respondem às pressões formais e informais para que as empresas atendam a requisitos de sustentabilidade socioambiental com os quais, nem sempre, estão verdadeiramente comprometidas. Os discursos constroem territórios - reais e/ou simbólicos; dos territórios construídos, derivam discursos.

\section{Poder das Narrativas}

Partindo-se do pressuposto de que os discursos criam realidades em razão da tríade "linguagem, poder e ideologia" (FAIRCLOUGH, 2016), para se contribuir no sentido da compreensão da ação das empresas fumageiras no território do Vale do Rio Pardo, procedeu-se a uma análise crítica dos discursos oficiais das agroindústrias fumageiras presentes no território.

A análise foi desenvolvida a partir de uma simplificação da estrutura analítica proposta por Bhaskar ${ }^{13}$ [BHASKAR, 1986; CHOULIARAKI \& FAIRCLOUGH, 1999 apud FAIRCLOUGH, 2005]), compreendendo:

\footnotetext{
${ }^{13}$ Na presente pesquisa, em razão de seus objetivos - os quais se distanciam de uma análise linguística, adotou-se uma simplificação com relação à estrutura completa de Análise Crítica do Discurso (ACD) proposta por Bhaskar, que prevê, para além da estrutura analítica: análise interacional; análise interdiscursiva; análise linguística e semiótica.
} 
(i) Ênfase em um problema social com aspecto semiótico;

(ii) Obstáculos para que o problema seja resolvido pela análise da rede de práticas, das relações de semiose e do discurso;

(iii) A ordem social (rede de práticas) como problema ${ }^{14}$;

(iv) Maneiras possíveis para superação dos obstáculos;

(v) Reflexão crítica sobre a análise ${ }^{15}$.

Considerando-se a estrutura proposta, a análise realizada no ano de 2018 , com base em relatórios acessados em $2017^{16}$, permitiu a aproximação do cenário descrito a seguir.

Como problema social com aspecto semiótico, destaca-se a apropriação, por parte das fumageiras, dos bens ambientais presentes no território estudado, gerando externalidades ambientais negativas, as quais não são contabilizadas nos relatórios econômicos das empresas e, igualmente, não são publicizadas em seus relatórios de sustentabilidade e/ou responsabilidade social corporativa.

Os impactos negativos sobre os sistemas ambiental e social - inerentes a uma monocultura voltada à exportação, baseada no uso intensivo de fertilizantes sintéticos e agroquímicos - são obscurecidos por um discurso historicamente construído e culturalmente aceito, disseminado não apenas pelas empresas, mas também pelos produtores rurais e pela sociedade regional em geral, baseado na sustentabilidade econômica oferecida pela agroindústria do tabaco e nas, supostas, responsabilidade social e ambiental das empresas.

Os quatorze relatórios analisados, produzidos e publicizados pelas quatorze empresas associadas ao Sindicato Interestadual da Indústria do Tabaco (SindiTabaco) apresentam, em um ou mais momentos, discursos que destacam uma imagem comprometida com a sustentabilidade ambiental e a segurança física (especialmente relacionada à saúde) dos produtores rurais de tabaco.

Como exemplo, trecho do Relatório de Responsabilidade Social da "Fumageira $1^{17 ",}$ que apresenta a visão da empresa:

\footnotetext{
14 A discussão desta categoria de análise é feita no item intitulado "Territorialização, Conflitos, Riscos Socioambientais e Injustiça Ambiental: As Empresas Fumageiras como Atores", no presente artigo.

${ }^{15}$ A reflexão crítica sobre a análise, no presente artigo, é tecida nas considerações Transitórias: os Saberes Ambientais como Mote da Transformação.

${ }^{16}$ Os relatórios foram acessados em 2017, porém, em alguns casos, tratavam-se de relatórios desatualizados, concernentes a anos anteriores.

${ }^{17}$ Para preservar a identidade das empresas, seus nomes foram omitidos, sendo substituídos por "Fumageira 1 "; "Fumageira 2" e assim sucessivamente.
} 
[Fumageira 1] has a global sustainability program rooted in three pillars: Producers, People and Planet. We are invested in responsible crop production - that is, crop production which ensures the economic viability for the grower, provides a safe working atmosphere for those involved in crop production and minimizes negative environmental impact. Our strategy is to provide secure and sustainable livelihoods for our contracted growers and their communities, with a low environmental impact. This approach involves improving the efficiency of our operations as well as working with our contracted growers to help them continuously improve their own agricultural and labor practices. ${ }^{18}$

A Fumageira 2, em texto introdutório ao Relatório de Responsabilidade Social, destaca:

Para produzir tabacos de qualidade e na quantidade necessária para atender aos seus clientes, a [Fumageira 2] desenvolve inúmeras ações que identificam sua visão administrativa voltada às questões ambientais, buscando melhorar a qualidade de vida da família dos produtores rurais. [...]

A empresa utiliza sementes de alta tecnologia, aprovadas internacionalmente e não geneticamente modificadas, com características de alta produtividade e resistência a doenças, possibilitando, assim, diminuir a utilização de defensivos agrícolas nas lavouras. Na produção de mudas é utilizado o sistema float, de fácil manejo, reduzindo substancialmente os custos e o uso de agrotóxicos.

Nas orientações técnicas à lavoura é recomendado o máximo de cuidado com a proteção do solo, através de técnicas como plantio direto, cultivo mínimo, cobertura de solo, subsolagem, terraceamento, etc. O produtor é orientado a utilizar defensivos somente na quantidade recomendada e quando extremamente necessário.

Esses discursos fortalecem a manutenção e reprodução de um modelo entrópico de produção, que gera riscos socioambientais e injustiça ambiental. Mascarando a realidade, os discursos contribuem para a quase inexistência de conflitos quanto aos usos do território e seus recursos, bem como quanto à distribuição de riscos referentes à monocultura de precisão. Quando os riscos não são percebidos, não existem conflitos.

As análises da rede de práticas na qual se inserem as agroindústrias do fumo e da relação de semiose com outros elementos dentro das práticas particulares em questão, permitem evidenciar obstáculos que se referem ao próprio macroprocesso de dominação exercido pelo capital. A região do Vale do Rio Pardo compõe um cenário onde se pode identificar a presença massiva de pequenas propriedades rurais familiares, relacionadas à rede agroindustrial do tabaco pela dependência econômica, que se estabelece por meio de financiamentos para a produção e compra de insumos e equipamentos. As agroindústrias também são as fornecedoras das sementes geneticamente modificadas ${ }^{19}$, dos fertilizantes

\footnotetext{
${ }^{18}$ O relatório da Fumageira 1, empresa transnacional, é publicado somente em Inglês.

${ }^{19}$ Somente uma das empresas estudadas afirma em seu relatório que não se utiliza de sementes geneticamente modificadas, a Fumageira 2.
} 
químicos para melhoramento do solo e dos agroquímicos para combater pragas e tornar mais eficiente a produção. A dependência econômica do produtor rural - e de toda a região, em última instância - com relação às fumageiras, cria uma relação de poder assimétrica e verticalizada, bastante difícil de ser rompida e mesmo de ser questionada.

A análise crítica do discurso ou a semiose em si, permitiu identificar a adoção de termos e símbolos que visam a produção de sentidos, induzindo à afirmação de uma imagem de responsabilidade socioambiental. Procurando-se analisar a estrutura do discurso e as intertextualidades, observou-se ${ }^{20}$ marcas discursivas que remetem à personalização do leitor e da instituição:

[Fumageira 9] Você, produtor rural, é a parte mais importante de tudo o que representamos $[\ldots]$

Simulação de uma relação conversacional e autopromoção das empresas:

[Fumageira 2] Como alcançamos a excelência? Utilizando as mais modernas técnicas de produção agrícola, com um atendimento baseado em respeito, confiança e amizade, junto ao produtor, o orientador agrícola da [Fumageira 2] desenvolve um trabalho de assistência técnica na propriedade rural, de acordo com as necessidades dos produtores e da cultura.

Gênero híbrido de escrita, entre a redação científica e o senso comum:

[Fumageira 5] Assegurar o controle sobre os aspectos e possíveis impactos ambientais originários das atividades da [Fumageira 5] através de ações e equipamentos como: Estação de Tratamento de Efluentes, a qual devolve à natureza, de forma não poluente, os efluentes líquidos gerados em suas atividades; Utilização de produtos de limpeza biodegradáveis; Coleta seletiva de lixo. Todo o lixo gerado é separado e destinado para empresas licenciadas por órgãos ambientais; Programas de conscientização sobre o meio ambiente junto aos seus funcionários, prestadores de serviço e produtores; Utilização de máquinas equipadas com recursos tecnológicos que propiciam baixo consumo de energia elétrica.

\footnotetext{
${ }^{20}$ Neste ponto do texto, são citados alguns trechos dos relatórios consultados que exemplificam cada categoria discursiva.
} 
Mercantilização do discurso:

[Fumageira $11^{21}$ - discurso que afirma, embora utilize subterfúgios linguísticos que focam apenas na questão da melhoria da produtividade, que a empresa fiscaliza a produção de modo constante, utilizando tecnologias de ponta] 'In: 2011, [a Fumageira 11] its award-winning Grower's Management System (GMS), a software tool developed in-house which provides real-time visibility into our grower base. This tool has been enormously beneficial in helping our agronomists and leaf technicians identify the greatest risks and opportunities for improvement in agricultural and labor practices. In addition, we are better able to monitor for compliance and track trends year over year'.

A luta simbólica pela naturalização do senso comum aparece constantemente nos relatórios analisados, especialmente quando se enfatiza, repetidamente, nos textos, que a empresa, [Fumageira 8] "como suas práticas atestam" ${ }^{22}$, sempre trabalha voltada à sustentabilidade socioambiental", [Fumageira 13] "garantindo a saúde do trabalhador" e [Fumageira 6] a "preservação ambiental".

A discussão socioambiental se desenha em torno de programas definidos pelo léxico considerado relevante para a agroindústria, valendo-se de marcos linguísticos com significado difuso (duplo, em alguns momentos) ou mesmo usando termos de modo incorreto.

Como exemplo de termos de significado difuso, tem-se 'sustentabilidade' e seu correlato "sustentável", que aparecem 56 vezes nos discursos analisados; esses termos costumam ser relacionados diretamente, pelo senso comum, a boas práticas ambientais, mas que aparecem, na totalidade dos discursos analisados, pelo menos em um trecho de cada documento, relacionados exclusivamente à sustentabilidade econômica (financeira): [Fumageira 3: 'A grande rentabilidade do tabaco garante um modelo sustentável de produção".

Com relação a termos utilizados de maneira incorreta, encontra-se, por exemplo, "reflorestamento" (aparece 29 vezes nos documentos analisados), sendo utilizado como sinônimo de plantio de madeira de corte, para consumo nas estufas de secagem de fumo nas propriedades rurais (o erro acontece em 20 das 29 ocorrências). Sabe-se que o uso

\footnotetext{
${ }^{21}$ Relatório disponibilizado somente em Inglês.

22 Os relatórios enfatizam que utilizar madeiras de plantações comerciais, reduzir o uso de agroquímicos, incentivar os produtores a usarem equipamentos de segurança - práticas comumente adotadas e, em alguns casos, exigidas por legislação e aceitas pelo senso comum - tonam a empresa ambiental e socialmente responsável.
} 
correto do termo se refere à recomposição da mata nativa, sem finalidade de uso da madeira.

Para além dos exemplos citados, ainda compondo o quadro discursivo relacionado pelo senso comum a boas práticas socioambientais, identificou-se, nos 14 discursos analisados, o uso de termos como "justiça" (oito vezes) e seu derivado "justo" (11 vezes), "desenvolvimento sustentável" (25 vezes), “crescimento sustentável" (seis vezes), "segurança" (nove vezes) e seu derivado "seguro" (sete vezes), "controle da poluição" (seis vezes), "controle da contaminação" (quatro vezes). Os termos são utilizados em contextos variados, claramente buscando o convencimento do leitor quanto ao compromisso das empresas com a viabilidade econômica, a justiça social e a sustentabilidade ambiental.

A análise crítica do discurso das fumageiras fornece instrumentos para se pensar em movimentos possíveis para a superação dos obstáculos. O quadro que emerge como cenário mais positivo, a partir das análises proporcionadas pela pesquisa, nos parece calcado na construção coletiva e cooperativa de estratégias horizontalizadas, voltadas ao desenvolvimento socioeconômico - em contraponto ao crescimento econômico sem a observância de limites e com distribuição de renda limitada.

O contraponto à homogeneição globalizadora dos territórios, promovida pelo capital e personificada pelas empresas, especialmente as transnacionais, está no fortalecimento da escala regional; não para que as regiões se contraponham ou resistam à globalização, mas para que fortaleçam particularidades e identidades, podendo inserir-se no campo de forças do mercado-mundo de modo mais justo.

Neste sentido, os estudos acerca do desenvolvimento da Região do Vale do Rio Pardo, contribuem para o conhecimento da base territórial regional, ecologicamente ${ }^{23}$ e culturalmente falando. Esse conhecimento, quando disseminado, gera poder às sociedades regionais: o poder de conhecer suas forças e fragilidades e, com base nesse conhecimento, aceitar ou não, juntar-se às forças indutoras do crescimento econômico.

O fortalecimento dos atores regionais é etapa indispensável para a elaboração de políticas econômicas de fortalecimento das regiões e promoção de seu desenvolvimento.

\footnotetext{
${ }^{23} \mathrm{O}$ conhecimento ecológico é fundante, uma vez que se refere à ciência sobre a base de recursos ambientais disponíveis para a produção, e, para além disso, porque trata de compreender a capacidade de suporte dos ecossistemas com relação ao provimento das funções gratuitas (disponibilidade de oxigênio, ciclagem de nutrientes, dentre outras), responsáveis pela manutenção da vida. Sem base de recursos não há produção, não há economia, e, em última análise, não há vida.
} 
Neste sentido, conhecer, em sentido mais profundo e simbólico, os discursos das empresas que territorializam o espaço; que se apropriam dos bens ambientais, convertendo-os em recursos de produção monocultora voltada à exportação e que geram externalidades socioambientais negativas que não são contabilizadas nos balanços econômicos, é etapa fundamental de empoderamento e transformação.

\section{Os Saberes ambientais como mote da transformação: algumas considerações finais}

Quando há hegemonia discursiva, o discurso se estabelece como monólogo. O silêncio eloquente ou a repetição mecânica, causados pelo desconhecimento do cenário completo e complexo, é terreno fértil para a dominação, estagnação e injustiças de toda ordem.

A pesquisa que resultou no presente artigo, surge da consideração de que uma análise crítica dos discursos disseminados pelas empresas que territorializaram, e seguem territorializando, a região do Vale do Rio Pardo (RS) - uma análise não ancorada no rigor da linguística, porém se valendo de algumas categorias da mesma - é indispensável para a compreensão da ação material do capital no território, e para a compreensão da dominação simbólica exercida pelas empresas na região.

No contexto de afirmação do mercado-mundo globalizado e globalizante, as forças homogeneizantes sufocam e anulam particularidades e identidades regionais que, se fortalecidas, podem garantir uma maior simetria no jogo de forças entre crescimento econômico e desenvolvimento socioambiental/econômico.

Não se trata de um movimento voltado para a expulsão das empresas do território ou para o estabelecimento/fortalecimento do antagonismo entre empresas e sociedade, mas de afirmar o desejo coletivo pela construção de espaços de esperança (David Harvey, 2004), a semeadura de outras soluções (Boaventura de Sousa Santos, 2005), trazendo as pessoas para o primeiro lugar (Amartya Sen e Bernardo Kliksberg, 2010), valendo-se da racionalidade ambiental (Enrique Leff, 2001) como laço que une duas necessidades: aquela que foi criada pelo modelo civilizatório adotado pela humanidade, e se refere a produzir e gerar renda, emprego e lucratividade; e a outra necessidade, que é primária e fundante, e está relacionada à manutenção das condições de existência da vida na biosfera terrestre. 
Discurso é ferramenta de poder, exercido por meio da narração da realidade. Sendo assim, aquele que narra escolhe qual realidade vai narrar, para quem e com qual/quais objetivos.

Deste modo, a pesquisa que origina o presente artigo deseja contribuir para a emergência de vozes plurais, com léxico próprio e adequado à compreensão da realidade pelo conjunto de seus atores.

\section{Referências}

ACSELRAD, H. As práticas espaciais e o campo dos conflitos ambientais. p. 13-35. In: Conflitos Ambientais no Brasil. Rio de Janeiro: Relume Dumará, 2004a.

ACSELRAD, H.; HERCULANO, S.; PÁDUA, J.A. A Justiça Ambiental e a Dinâmica das Lutas Socioambientais no Brasil - uma Introdução. P. 9-20. In: ACSELRAD, H.; HERCULANO, S.; PÁDUA, J. A. (org.). Justiça Ambiental e Cidadania. Rio de Janeiro: Relume Dumará, 2004-b.

AFUBRA - Associação de Fumicultores do Brasil. Evolução da Fumicultura na região Sul do Brasil. Disponível em: https://afubra.com.br/fumicultura-brasil.html. Acesso em: 28 mar. 2018.

ETGES, V. E. Prefácio. P.07-08. In: SILVEIRA, R. L. L. da. (org.) Tabaco, Sociedade e Território: Relações e Contradições no Sul do Brasil. Santa Cruz do Sul: EDUNISC, 2013.

FAIRCLOUGH, N. Critical Discourse Analysis as a Method in Social Scientific Research. In: WODAK and MEYER (org.). Methods of Critical Discourse Analysis. 2 ed. Londres: Sage, 2005. p. 121-138.

. Discurso e Mudança Social. 2 ed. Brasília: UNB, 2016.

FEE - Fundação de Economia e Estatística do Rio Grande do Sul. Estatísticas Populacionais. Disponível em: http://www.fee.rs.gov.br/perfilsocioeconomico/coredes/detalhe/?corede=Vale+do+Rio+Pardo. Acesso em 20 dez. 2016.

FEE - Fundação de Economia e Estatística do Rio Grande do Sul. Estatísticas Populacionais. Disponível em: http://www.fee.rs.gov.br/perfilsocioeconomico/coredes/detalhe/?corede=Vale+do+Rio+Pardo. Acesso em 15 jul. 2018.

HAESBAERT, R. O Mito da Desterritorialização. Do "Fim dos Territórios" à Multiterritorialidade. Rio de Janeiro: Bertrand Brasil, 2004. 
HARVEY, D. A Produção Capitalista do Espaço. São Paulo: Annablume, 2005.

Espaços de Esperança. São Paulo: Edições Loyola, 2004.

HARRIS, M. Teorías sobre la Cultura em la Era Posmoderna. Barcelona: Romanyà Press/Valls, 2004.

LATOUR, B. Crise. In: Jamais Fomos Modernos. Ensaio de Antropologia Simétrica. 3. Reimpressão. Rio de Janeiro: Editora 34, 2005. P. 7-17.

LEFF, E. Saber Ambiental. Sustentabilidade. Racionalidade. Complexidade. Poder. 3 ed. Rio de Janeiro: Vozes, 2001.

MARQUES, A. F. BUBLITZ, T. A. Spaces, Processes and Vulnerability Relations. In: Santa Cruz do Sul (RS) City: Building Paths in Environmental Justice Field. p. 580-591. In: Revista Eletrônica em Gestão, Educação e Tecnologia Ambiental. Santa Maria, v. 20, n. 1, jan. abr. 2016. Revista do Centro de Ciências Naturais e Exatas - UFSM.

RAMOS, M. P.; PAIVA, C. N. Á. Limitações e Possibilidades da Análise de Indicadores Regionais: O Caso do COREDE do Vale do Rio Pardo. P. 83-92. In: REDES. v. 10, n. 2 , maio/ago. 2005.

SANTOS, B. de S. (org.). Semear Outras Soluções. Os Caminhos da Biodiversidade e dos Conhecimentos Rivais. Rio de Janeiro: Civilização Brasileira, 2005.

SEN, A; KLIKSBERG, B. As Pessoas em Primeiro Lugar. A Ética do Desenvolvimento e os Problemas do Mundo. São Paulo: Companhia das Letras, 2010.

SILVEIRA, R. L. L. da. Apresentação. In: SILVEIRA, R. L. L. da. (org.) Tabaco, Sociedade e Território: Relações e Contradições no Sul do Brasil. Santa Cruz do Sul: EDUNISC, 2013. p. 9-15

SINDICATO INTERESTADUAL DA INDÚSTRIA DO TABACO - SindiTabaco. Empresas Associadas. Disponível em: http://www.sinditabaco.com.br/a-entidade/associadas/. Acesso: 23 maio, 2017. 